\title{
Anticancer effect of miR-96 inhibitor in bladder cancer cell lines
}

\author{
TING XU ${ }^{1,2^{*}}$, XIAO-WEN DU ${ }^{1 *}$, JUN-BIAO HU ${ }^{1}$, YONG-FENG ZHU ${ }^{1}$, HUI-LING WU ${ }^{1}$, \\ GUO-PING DAI ${ }^{1}$, YAO-MIN SHU ${ }^{1}$ and JUN OUYANG ${ }^{2}$ \\ ${ }^{1}$ Department of Urology, Jinhua People's Hospital, Jinhua, Zhejiang 321000; ${ }^{2}$ Department of Urology, \\ The First Affiliated Hospital of Soochow University, Suzhou, Jiangsu 215006, P.R. China
}

Received August 19, 2016; Accepted October 3, 2017

DOI: $10.3892 / \mathrm{ol} .2018 .7745$

\begin{abstract}
The present study aimed to investigate the role of microRNA-96 (miR-96) in the proliferation, invasion and apoptosis of bladder cancer cell lines, and the associated mechanisms. The expression of miR-96 and human ether-à-go-go-related (HERG1) potassium channel in the normal uroepithelium SV-HUC-1 cell line, and bladder cancer T24 and 5637 cell lines were examined using reverse transcription- polymerase chain reaction or/and western blotting. Transfection with miR-96 inhibitor or scrambled control (SC) was used to study the biological activities of miR-96 in bladder cancer cell lines. MTT, flow cytometric and Transwell assays were applied to detect cell viability, apoptosis and invasion, respectively. A dual-luciferase reporter assay was applied to determine the association between miR-96 and HERG1 expression. As demonstrated, miR-96 was highly expressed in the two bladder cancer cell lines, particularly in T24 cells. Following transfection with miR-96 inhibitor, miR-96 expression was significantly reduced in the T24 cell line, compared with SC. The miR-96 inhibitor suppressed cell proliferation and invasion, promoted apoptosis and arrested the cell cycle at the $\mathrm{G}_{1}$ phase. Consistently, HERG1 was also highly expressed in the two bladder cancer cell lines at the mRNA and protein level, but not in the normal uroepithelium cell line. The miR-96 inhibitor also significantly decreased HERG1 expression compared with SC. The results of the dual-luciferase reporter assay indicated that miR-96 directly targeted wild-type HERG1. In conclusion, miR-96 inhibitor exhibited anticancer effects on bladder cancer cells by inhibiting proliferation and invasion of cells, and promoting their apoptosis. HERG1 was an important target of miR-96. These
\end{abstract}

Correspondence to: Dr Jun Ouyang, Department of Urology, The First Affiliated Hospital of Soochow University, 188 Shizi Street, Suzhou, Jiangsu 215006, P.R. China

E-mail: ouyangjun8703@sina.com

*Contributed equally

Key words: microRNA-96, human ether-à-go-go-related gene, bladder cancer cell lines, proliferation, apoptosis results provided experimental evidence supporting miR-96 as a therapeutic target for patients with bladder cancer.

\section{Introduction}

Bladder cancer is one of the most common types of malignant tumors of the urinary and reproductive system, including bladder urothelial cell carcinoma, squamous cell carcinoma, adenocarcinoma and rare small cell carcinoma worldwide. Of these subtypes, bladder urothelial cell carcinoma accounts for $90 \%$ of cases. A series of pathogenic factors affect the occurrence of bladder cancer, including aging, smoking and environmental pollution (1). The mortality rate of bladder cancer is increasing, even in childhood $(1,2)$. The pathogenesis of bladder cancer is complex, and involves the activation of oncogenes and the inactivation of tumor suppressor genes. The imbalanced activation of oncogenes and tumor suppressor genes impairs the normal growth mechanism of cells, leading to unrestricted cell proliferation, and increased invasiveness $(3,4)$.

MicroRNAs (miRNAs/miRs) are a family of endogenous non-coding small RNA molecules with a length of 21-25 nucleotides. miRNAs function primarily through the targeted degradation of mRNAs and inhibition of translation into proteins. Therefore, miRNAs have numerous biological activities $(5,6)$. Notably, miRNAs perform critical functions in the occurrence and development of lung, liver, gastric, cervical, breast, and colon cancer $(7,8)$. Direct evidence has also documented the abnormal expression of miRNAs in bladder cancer tissue. miR-96 is a conserved miRNA that may be involved in the occurrence and development of bladder cancer $(9,10)$. Further research also demonstrated that miR-96 was highly expressed in bladder cancer tissue and the blood plasma obtained from patients with bladder cancer (11-13). Yamada et al (14) confirmed that miR-96 expression in urine samples from bladder urothelial carcinoma was significantly increased compared with that from healthy subjects. Therefore, miR-96 is considered to be an important tumor diagnostic marker for bladder cancer. However, to the best of our knowledge, the influence of miR-96 on tumor cell biology and its mechanisms have not been reported previously. In the present study, miR-96 was selected as the research target; the aim was to investigate the effects of miR-96 on bladder cancer cell proliferation, apoptosis, invasion and metastasis and underlying mechanisms. 


\section{Materials and methods}

Cell culture. Human bladder cancer cell lines, T24 and 5637 (American Type Culture Collection, Bethesda, MD, USA) were cultured in Dulbecco's modified Eagle's medium (DMEM; Gibco; Thermo Fisher Scientific, Inc., Waltham, MA, USA) supplemented with $10 \%$ fetal bovine serum (FBS; Hyclone; GE Healthcare Life Sciences, Logan, UT, USA) and $100 \mathrm{U} / \mathrm{ml}$ penicillin-streptomycin (Sigma-Aldrich; Merck $\mathrm{KGaA}$, Darmstadt, Germany) in $5 \% \mathrm{CO}_{2}$ at $37^{\circ} \mathrm{C}$. SV-HUC-1, a normal uroepithelium cell line, was also obtained from the American Type Culture Collection, and was used as the control. Cells at $60 \%$ confluence were used in the following experiments.

Reverse transcription-polymerase chain reaction ( $R T-P C R)$. Total RNA was extracted according to the instruction of the TRIzol kit (Takara Biotechnology Co., Ltd., Dalian, China) and the purity of RNA was confirmed by optical density (OD) at 280/260 nm. Following this, RNA was amplified using a one-step RT-PCR kit (Dalian Baosheng Biological Engineering Co., Ltd., Dalian, China) and PCR products were detected using $2 \%$ agarose gel electrophoresis. The primers were added into a $25-\mu 1$ PCR reaction system following a protocol of $94^{\circ} \mathrm{C}$ denaturation for $45 \mathrm{sec}, 59^{\circ} \mathrm{C}$ annealing for $45 \mathrm{sec}$ and $72^{\circ} \mathrm{C}$ extension $60 \mathrm{sec}$ for 35 cycles. The primers used are as follows: miR-96 forward, 5'-TTTGGCACTAGC ACATT-3' and reverse, 5'-TTTGGCACTAGCACATT-3'; human ether-à-go-go-related (HERG1) potassium channel forward, 5'-TCCAGCGGCTGTACTCGGGC-3' and reverse, 5'-TGGACCAGAAGTGGTCGGAGAACTC-3'; and GAPDH forward, 5'-AGCCACATCGCTCAGACA-3' and reverse 5'-TGGACTCCACGACGTACT-3'.

Cell transfection. When the confluence of T24 cells reached 50-70\%, Lipofectamine ${ }^{\mathrm{TM}} 2000$ (Thermo Fisher Scientific, Inc.) was applied to assist the transfection of scrambled control (SC) and miR-96 inhibitor. Then, $6 \mathrm{~h}$ later, the medium was changed to DMEM. The miR-96 inhibitor (5'-AGCAAAAAU GUGCUAGUGCCAAA-3') (1 $\mu \mathrm{l})$ and SC (5'-CAGUACUUU UGUGUAGUACAA-3') were synthesized using Shanghai GenePharma Co., Ltd. (Shanghai, China). Cells were then cultured in DMEM containing 10\% FBS for another $48 \mathrm{~h}$. RT-PCR was applied to detect miR-96 expression.

MTT assay. T24 cells were seeded in 96-well plates. When the cell confluence reached 50-70\%, Lipofectamine 2000 was applied to transfect cells with SC and miR-96 inhibitor, as aforementioned. At $6 \mathrm{~h}$ later, the medium was changed into DMEM. The cells were then cultured in DMEM containing 10\% FBS for another 24, 48 and $72 \mathrm{~h}$. An MTT assay was utilized to detect cell proliferation, as previously described (15). In total, $150 \mu 1$ DMSO (Sigma-Aldrich; Merck KGaA) was added to each well in order to dissolve formazan. The optical density (OD) was determined using a microplate reader at $570 \mathrm{~nm}$.

Flow cytometry. Following transfection with miR-96 inhibitor and SC for $48 \mathrm{~h}$, the T2 4 cells were collected for Annexin V-fluorescein isothiocyanate/propidium iodide (PI) staining using the Annexin V-FITC Apoptosis Detection kit (cat. no. C1062; Beyotime Institute of Biotechnology, Ningbo, China) and the proportion of apoptotic cells was detected within $1 \mathrm{~h}$ using a FACSCalibur flow cytometer (BD Biosciences, Franklin Lakes, NJ, USA) and data were analyzed using CellQuest Pro (version 5.1; BD Biosciences, Franklin Lakes, NJ, USA). Following transfection for $48 \mathrm{~h}$, the cells were collected for PI staining and the cell cycle distribution was assessed by FACSCalibur (BD Biosciences) within $1 \mathrm{~h}$ of staining.

Transwell assay. Following transfection with miR-96 inhibitor and SC for $48 \mathrm{~h}, \mathrm{~T} 24$ cells $\left(3 \times 10^{3}\right)$ were digested and seeded into the upper chamber of Transwell with one-day starvation of FBS (Hyclone; GE Healthcare Life Sciences). The lower chamber contained DMEM with $10 \%$ FBS. the cells were seeded in the upper chamber. The lower chamber contained only DMEM. At $48 \mathrm{~h}$ after seeding, the cells in lower chamber were fixed in $4 \%$ paraformaldehyde at room temperature for $30 \mathrm{~min}$ and stained with $1 \%$ crystal violet for $5 \mathrm{~min}$ at room temperature. Images were captured using a light microscope (magnification, x200). At least five fields in each image were counted.

Western blotting. Following transfection with miR-96 inhibitor or SC for $48 \mathrm{~h}$, the cells were collected for biochemical experiments. Protein concentration was quantified using the BCA method. An equal amount of protein per lane $(20 \mu \mathrm{g})$ separated using 10\% SDS-PAGE. Following electrophoresis, proteins were transferred to a nitrocellulose membrane. Non-specific protein binding was blocked with $4 \%$ non-fat milk ( $2 \mathrm{~h}$ at room temperature). Membranes were incubated with anti-HERG1 (1:1,000; cat. no. ab196301; Epitomics; Abcam, Cambridge, MA, USA) and anti-GAPDH (1:1,000; cat. no. AG019; Beyotime Institute of Biotechnology, Haimen, China) primary antibodies. Subsequent to rinsing with $0.1 \%$ phosphate-buffered saline $(0.1 \%$ Tween- 20$)$, the membranes were incubated with a horseradish peroxidase-labeled secondary antibody (1:100; cat. no. ab131368; Abcam) at room temperature for $2 \mathrm{~h}$. The signal was detected using an Enhanced Chemiluminescence Detection kit (GE Healthcare, Chicago, IL, USA) and scanned using ChemiDoc ${ }^{\mathrm{TM}}$ XRS (Bio-Rad Laboratories, Inc., Hercules, CA, USA). The densities of the blots were analyzed using Quantity One analysis (version 1.4.6; Bio-Rad Laboratories, Inc.).

Dual-luciferase reporter assay. T24 cells $\left(3 \times 10^{5}\right)$ were seeded into 24-well plates and transfected with miR-96 and/or plasmid HERG1 using Lipofectamine 2000 according to the manufacturer's protocol, as aforementioned. Plasmids (cat. no. 60847; Wuhan Miaoling Biotech Science Co., Ltd., Wuhan, China) encoding an effective sequence to overexpress wild-type or mutant HERG1 were constructed. Experiments were divided into four groups: miR-96 inhibitor + wild-type HERG1 [pGL-ENNRA 3'-untranslated region (3'UTR)-Wt], SC + wild-type HERG1, miR-96 inhibitor + mutated HERG1 (pGL-ENNRA 3'UTR-Mut) and SC + mutated HERG1 (Shanghai Jima Industrial Co., Ltd., Shanghai, China). A Dual-Luciferase ${ }^{\circledR}$ Reporter Assay system (cat. no. E1960; Promega Corporation, Madison, WI, USA) was used to detect luciferase activity. Following transfection for $24 \mathrm{~h}$, the medium was removed, cells were washed with PBS 
Table I. miR-96 inhibitor arrests the cell cycle at the $\mathrm{G}_{1}$ phase and induces apoptosis in T24 cells.

\begin{tabular}{lcccccc}
\hline & \multicolumn{3}{c}{ Cell cycle, $\%$} & & \multicolumn{2}{c}{ Apoptosis, \% } \\
\cline { 2 - 3 } \cline { 6 - 7 } Group & $\mathrm{G}_{1}$ & $\mathrm{~S}$ & $\mathrm{G}_{2}$ & & Early & Late \\
\hline SC & $68.38 \pm 6.69$ & $20.13 \pm 2.01$ & $11.49 \pm 1.15$ & & $3.35 \pm 0.32$ & $8.29 \pm 1.83$ \\
miRI-96 & $87.37 \pm 8.46^{\mathrm{a}}$ & $6.13 \pm 0.56^{\mathrm{a}}$ & $6.50 \pm 0.58^{\mathrm{a}}$ & & $12.28 \pm 0.28^{\mathrm{a}}$ & $19.46 \pm 1.92^{\mathrm{a}}$ \\
\hline
\end{tabular}

${ }^{\text {a}} \mathrm{P}<0.01$, compared with SC. SC, scrambled control; miRI-96, microRNA-96 inhibitor.

and $100 \mu \mathrm{l}$ passive lysis buffer (provided by the Dual-Luciferase ${ }^{\circledR}$ system) was added and incubated for $10 \mathrm{~min}$. Following centrifugation $(11,656 \mathrm{x} \mathrm{g})$ for $10 \mathrm{~min}$ at $4^{\circ} \mathrm{C}$ and the supernatant was collected. Next, $20 \mu \mathrm{l}$ supernatant and $100 \mu \mathrm{l}$ luciferase assay reagent were mixed. Firefly luciferase activity was determined using a Glomax 20/20 fluorescence luminometer. Next, $100 \mu \mathrm{l}$ Stop \& Glo reagent (provided by the Dual-Luciferase system) was added to detect Renilla luciferase activity, to which the data were normalized.

Statistical analysis. The data are presented as the mean \pm standard deviation. Statistical analyses of the data were performed using one-way analysis of variance followed by a Bonferroni post hoc test or unpaired Student's t-test (version 17; SPSS, Inc., Chicago, IL, USA). P $<0.05$ was considered to indicate a statistically significant difference.

\section{Results}

miR-96 is highly expressed in bladder cancer cell lines. As presented in Fig. 1, miR-96 was highly expressed in T24 and 5,637 cells, particularly in T24 cells. As a control, miR-96 was rarely expressed in the uroepithelium SV-HUC-1 cell line. In the subsequent experiments, T24 was selected as the cell line to be used.

Transfection with miR-96 inhibitor suppresses cell proliferation, induces apoptosis, arrests cell cycle and inhibits cell invasion. Following transfection with miR-96 inhibitor for 6 h, expression miR-96 was markedly reduced (Fig. 2A). The effects of miR-96 inhibitor transfection on cell viability were assessed. As demonstrated using an MTT assay, cell viability was significantly reduced in cells transfected with the miR-96 inhibitor 24, 48 and $72 \mathrm{~h}$ after transfection, compared with those transfected with SC (Fig. 2B). Following transfection with miR-96 inhibitor for $48 \mathrm{~h}$, the proliferation inhibition was $\sim 50 \%$, and therefore, the 48 -h time point was selected for the other experiments. The proportion of apoptosis was detected using Annexin V-FITC/PI staining. Compared with cells transfected with SC, miR-96 inhibitor significantly increased the apoptosis rate (Fig. 2C and Table I). PI staining revealed that transfection with the miR-96 inhibitor arrested the cell cycle at the $\mathrm{G}_{1}$ phase (Fig. 2D and Table I). In addition, the Transwell assay demonstrated that transfection with a miR-96 inhibitor markedly decreased the cell invasion rate (Fig. 2E).

HERG1 is highly expressed in bladder cancer cell lines. As presented in Fig. 3, HERG1 protein and mRNA was highly
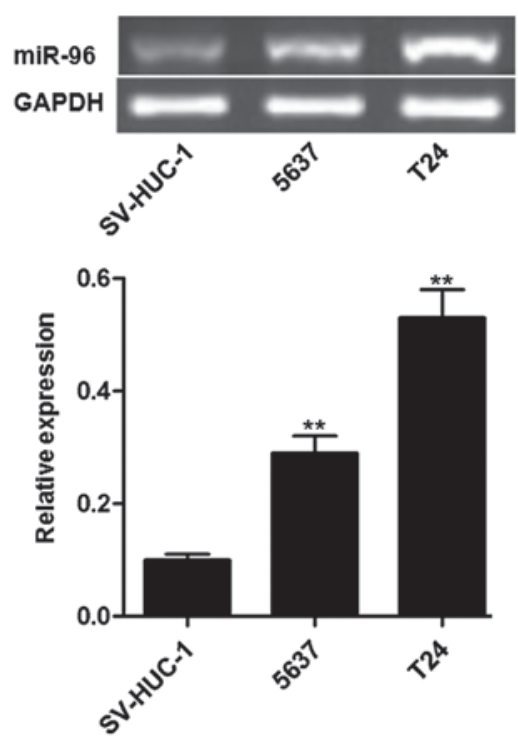

Figure 1. miR-96 is highly expressed in bladder cancer cell lines. ${ }^{* *} \mathrm{P}<0.01$ vs. SV-HUC-1 cells. miR-96, microRNA-96.

expressed in the bladder cancer T24 and 5,637 cell lines, but not in uroepithelium SV-HUC-1 cells.

miR-96 inhibitor regulates HERG1 expression in T24 cells. As miR-96 and HERG1 were highly expressed in bladder cancer cell lines, whether HERG1 was regulated by the expression of miR-96 was investigated. The T24 cell line was selected for use in these experiments. As demonstrated in Fig. 4, transfection with the miR-96 inhibitor significantly decreased HERG1 expression at the mRNA and protein level. To assess the direct regulation of HERG1 by miR-96, a dual-luciferase reporter assay was performed. As demonstrated in Fig. 5, transfection with the miR-96 inhibitor significantly decreased the relative fluorescence in the group transfected with the wild-type HERG1 3'UTR compared with the SC group.

\section{Discussion}

The pathogenesis of cancer is a complex process; various aspects affect its genesis and development. A commonly held view is that the imbalanced expression of oncogenes and tumor suppressor genes contributes to tumor cell proliferation, and invasion. Genes promoting the tumor development are known as oncogenes and the opposite are considered tumor suppressor genes (16). miRNAs are a class of highly conserved small RNAs that bind the 3'-UTR region of its 

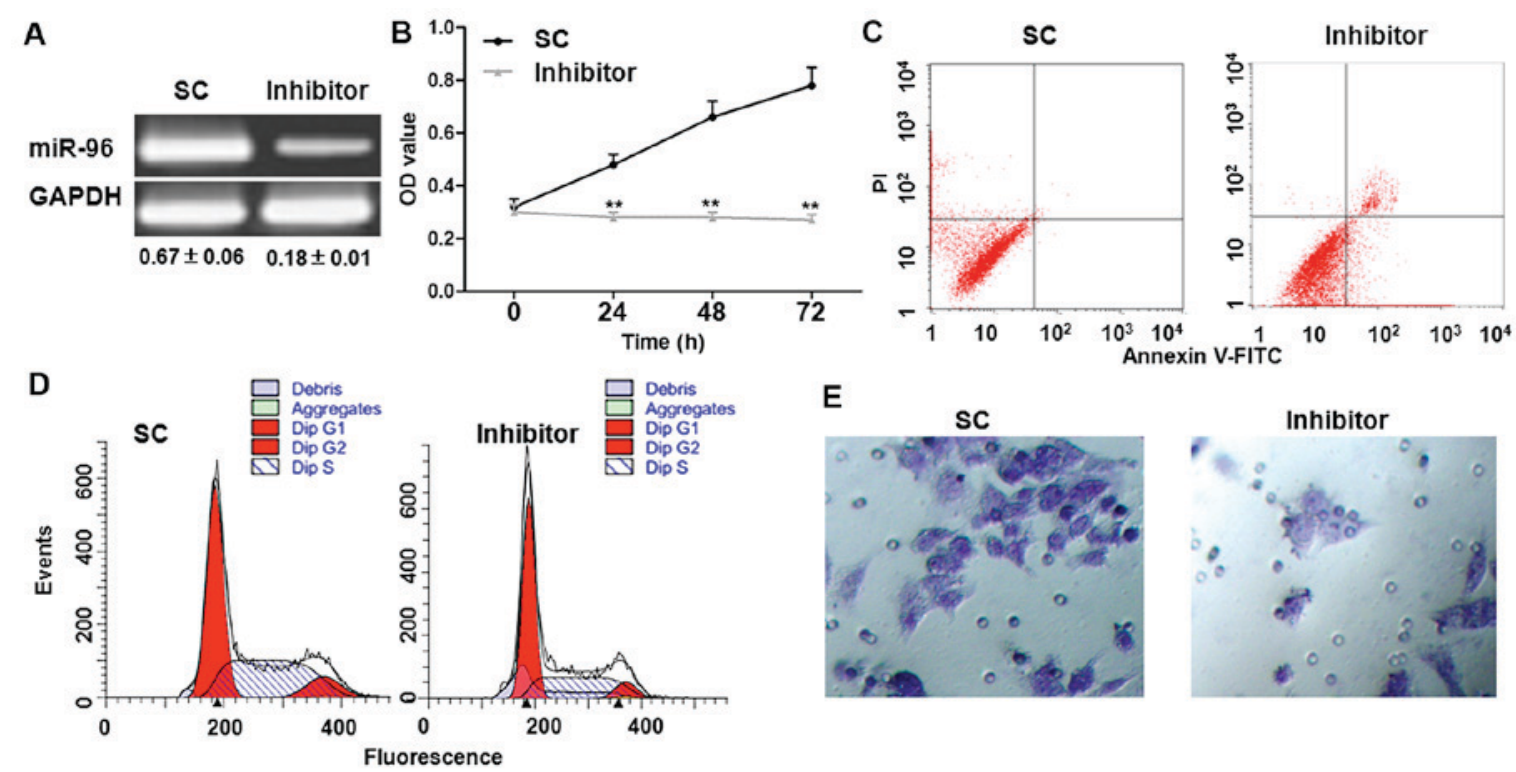

E
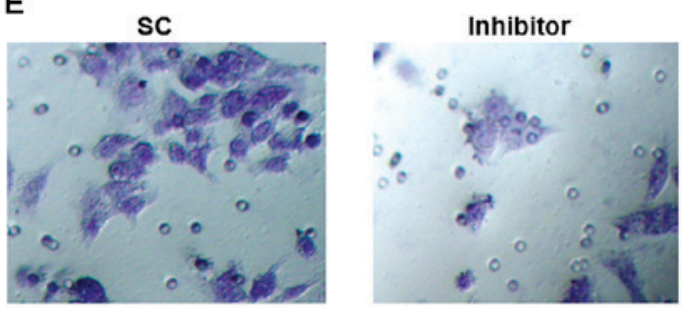

Figure 2. Effect of miR-96 inhibitor on cell biological activities in T24 cells. (A) miR-96 inhibitor decreased miR-96 expression. (B) miR-96 inhibitor suppressed cell proliferation. (C) miR-96 inhibitor induced apoptosis. (D) miR-96 inhibitor arrested cell cycle. (E) miR-96 inhibitor prohibited cell invasion (magnification, $\mathrm{x} 200$ ). ${ }^{* *} \mathrm{P}<0.01$ vs. SC. miR-96, microRNA-96; SC, scrambled control; FITC, fluorescein isothiocyanate; PI, propidium iodide.

A
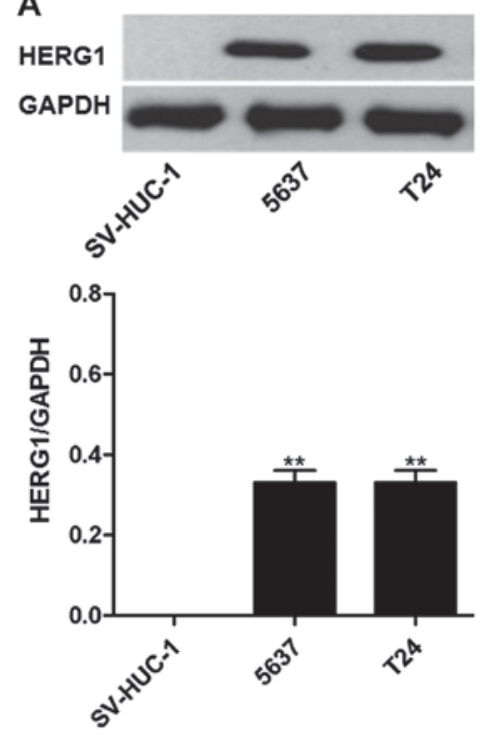

B

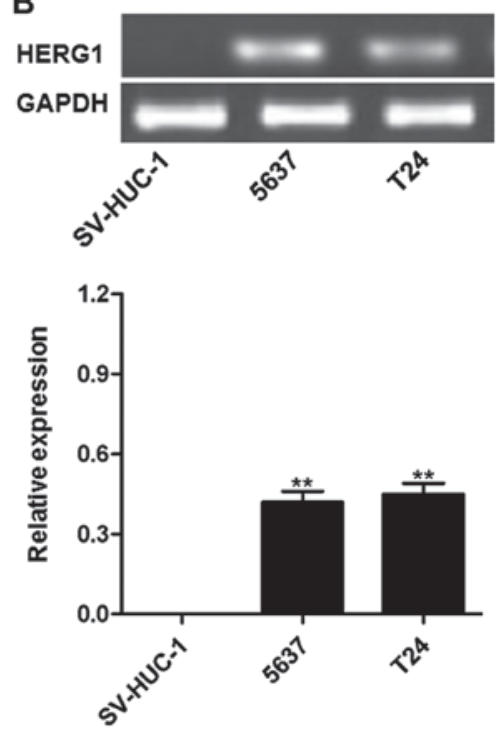

Figure 3. HERG1 is highly expressed in bladder cancer cell lines. (A) Protein level; (B) mRNA level. "* P<0.01 vs. SV-HUC-1 cells. HERG1, human ether-à-go-go-related.

target gene and regulate the expression of target genes. The present study demonstrated that miR-96 was a potential pro-oncogenic factor in bladder cancer cells. Inhibition of miR-96 expression was able to suppress cellular proliferation and invasion, promote apoptosis, and arrest the cell cycle at the $\mathrm{G}_{1}$ phase.

Recent studies have indicated that miRNAs function either as oncogenes or tumor suppressor genes, regulating the proliferation, apoptosis, differentiation, migration and invasion of tumor cells $(17,18)$. miR-96 belongs to the miR-183 family, the other two members of which are miR-182 and miR-183. These three miRNAs are found at similar locations in the genome. miR-96 is located at human chromosome locus 7q32.2, and the amplification of human chromosome 7 is important in lung cancer (19), hepatocellular carcinoma (20), prostate cancer (21), gastric cancer (22), esophageal cancer (23), breast cancer (24) and other types of tumor (9-13). miR-96 is highly expressed in those types of cancer and has been considered to be an oncogenic miRNA (25). Han et al (9) applied the gene expression microarray to validate that miR-96 expression was upregulated in bladder cancer tissue. Yoshino et al (13) also confirmed that miR-96 was highly expressed in bladder cancer tissue. Scheffer et al (12) confirmed that the expression of 22 miRNAs in bladder cancer tissues was upregulated, including miR-96. Kriebel et al (11) reported that the expression of plasma miR-96 in patients with bladder cancer was significantly increased. Eissa et al (26) demonstrated that miR-96 was highly expressed in bladder cancer tissues, but 
A
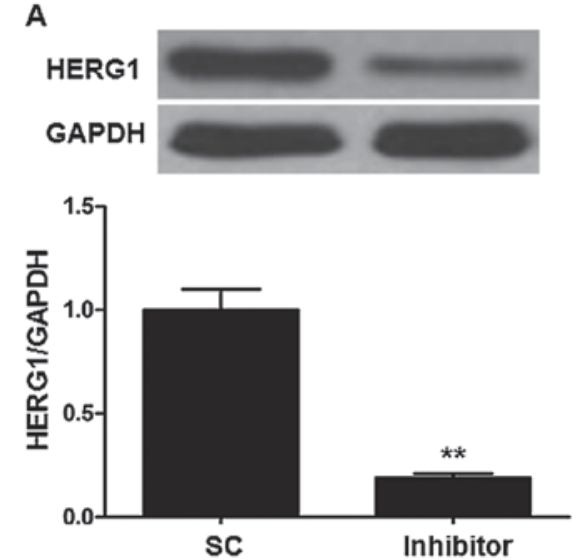

B
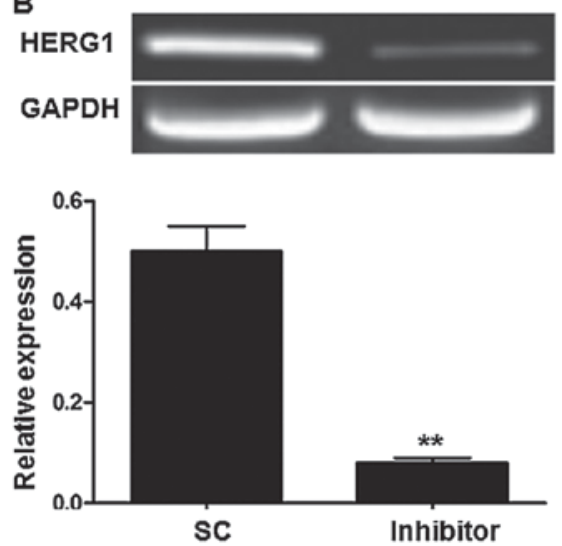

Figure 4. miR-96 inhibitor suppresses HERG1 expression in the T24 cell line. (A) Protein level; (B) mRNA level. ** P<0.01 vs. SC. miR-96, microRNA96; HERG1, human ether-à-go-go-related; SC, scrambled control.

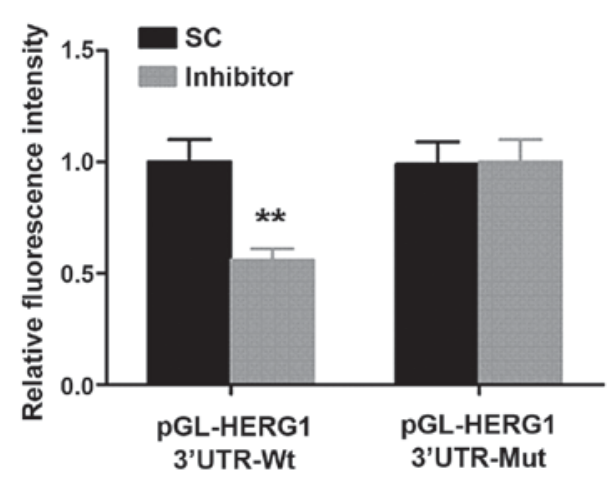

Figure 5. Luciferase report assay reported the association between miR-96 and HERG1. ${ }^{* *} \mathrm{P}<0.01$ vs. Pgl-HERG1 3'UTR-Wt. miR-96, microRNA96; HERG1, human ether-à-go-go-related; 3'UTR, 3'-untranslated region; Wt, wild-type.

not in benign bladder tumors. An additional report stated that miR-96 levels in the urine samples of patients with bladder cancer were increased (14). Therefore, it appears that miR-96 may serve important roles in the development and progression of bladder cancer. The present study demonstrated that miR-96 expression was upregulated in bladder cancer cell lines. These cell lines served as in vitro models, allowing for the study of the biological activity of miR-96 in bladder cancer.

In the present study, RT-PCR was used to detect miR-96 expression, which demonstrated high expression of miR-96 in normal bladder cells, particularly in bladder cancer cells. In the subsequent experiments, transfection with miR-96 inhibitor was found to suppress the cell proliferation and invasion, promote apoptosis and arrest the cell cycle at the $\mathrm{G}_{1}$ phase. Tumor cells must complete the cell cycle to replicate. Thus, cells that do not pass the $\mathrm{G}_{1}$ checkpoint 'loop out' of the cell cycle and into a resting state termed the $G_{0}$ phase. Data from the present study were consistent with a previously published study, in which it was verified that transfection with miR-96 inhibitor arrested the Panc- 1 cells at the $G_{1}$ phase and inhibited cellular proliferation (27). Apoptosis is a process of programmed cell death that occurs in multicellular organisms. In tumor cells, apoptosis is impaired, leading to unrestricted cell proliferation (28). Apoptosis is a method of eliciting cell death of cancer cells during chemotherapy or radiotherapy (29). The present study also found that miR-96 inhibitor promoted apoptosis of bladder cancer cells. In addition, transfection with the miR-96 inhibitor also prohibited the migration of bladder cancer cells. Consistently, Yu et al (30) also verified that transfection with the miR-96 inhibitor suppressed the invasion of renal cancer cell lines Caki-1 and 786-O.

Previous studies indicated that potassium ion channels serve important roles in the process of cellular proliferation $(31,32)$. In addition, calcium and chloride channels also have roles in the occurrence and development of tumors (33). The HERG1 channel is a potassium ion channel and a member of the fast delayed rectifier voltage-gated potassium ion family. HERG1 is located on chromosome 7q35-36 and was identified by Warmke and Ganetzky in 1994 (34) in Drosophila and in mammals. HERG1 consists of six transmembrane proteins, and is inward-rectifying and ion-selective. HERG1 regulates the entry of calcium into the cell, promotes calcium second messenger signaling transduction, regulates cytoskeletal changes, and alters cellular proliferation and migration $(31,32)$. HERG1 was initially reported to serve important roles in the process of repolarizing cardiac membrane potential (32). HERG1 was identified to be highly expressed in various tumor tissues, and was closely associated with tumor cell proliferation, apoptosis, differentiation, migration and invasion (35-37).

Downregulation of HERG1 in tumor cells can inhibit the proliferation, migration and invasion of tumor cells, all of which are malignant biological activities (38). The present study screened the expression of HERG1 in bladder cancer T24 and 5,637 cell lines, and the normal uroepithelium SV-HUC-1 cell line. The results of the current study revealed that HERG1 expression was significantly increased in bladder cancer cell lines compared with that in SV-HUC-1 cells. Bioinformatic analysis has demonstrated that HERG1 may be a target gene of miR-96 (39). The present study also utilized a dual luciferase reporter assay to verify that HERG1 was a target gene of miR-96. In addition, results of western blot analysis and RT-PCR also revealed that miR-96 inhibitor significantly reduced HERG1 expression.

The present study demonstrated that miR-96 was highly expressed in bladder cancer cell lines. miR-96 inhibition 
resulted in a number of anticancer effects on bladder cancer cells, including inhibition of proliferation and invasion, and promotion of apoptosis. Notably, evidence revealed that HERG1 was a target of miR-96. These results provided experimental evidence that support the role of miR-96 as a therapeutic target for bladder cancer.

\section{References}

1. Gan X, Lin X, He R, Lin X, Wang H, Yan L, Zhou H, Qin H and Chen G: Prognostic and clinicopathological significance of downregulated p16 expression in patients with bladder cancer: A systematic review and meta-analysis. Dis Markers 2016: $5259602,2016$.

2. Yin M, Joshi M, Meijer RP, Glantz M, Holder S, Harvey HA, Kaag M, Fransen van de Putte EE, Horenblas S and Drabick JJ: Neoadjuvant chemotherapy for muscle-invasive bladder cancer: A systematic review and two-step meta-analysis. Oncologist 21: 708-715, 2016.

3. Cauberg Evelyne CC, de la Rosette JJ and de Reijke TM: Emerging optical techniques in advanced cystoscopy for bladder cancer diagnosis: A review of the current literature. Indian J Urol 27: 245-251, 2011.

4. Fahmy N, Lazo-Langner A, Iansavichene AE and Pautler SE: Effect of anticoagulants and antiplatelet agents on the efficacy of intravesical BCG treatment of bladder cancer: A systematic review. Can Urol Assoc J 7: E740-E749, 2013.

5. Mizuguchi Y, Takizawa T, Yoshida H and Uchida E: Dysregulated miRNA in progression of hepatocellular carcinoma: A systematic review. Hepatol Res 46: 391-406, 2016.

6. Wang QX,Zhu YQ,Zhang H and Xiao J: Altered MiRNA expression in gastric cancer: A systematic review and meta-analysis Cell Physiol Biochem 35: 933-944, 2015.

7. Gambari R, Brognara E, Spandidos DA and Fabbri E: Targeting oncomiRNAs and mimicking tumor suppressor miRNAs: Nuew trends in the development of miRNA therapeutic strategies in oncology (Review). Int J Oncol 49: 5-32, 2016.

8. Srivastava K and Srivastava A: Comprehensive review of genetic association studies and meta-analyses on miRNA polymorphisms and cancer risk. PLoS One 7: e50966, 2012.

9. Han Y, Chen J, Zhao X, Liang C, Wang Y, Sun L, Jiang Z, Zhang Z, Yang R, Chen J, et al: MicroRNA expression signatures of bladder cancer revealed by deep sequencing. PLoS One 6: e18286, 2011.

10. Wu Z, Liu K, Wang Y, Xu Z, Meng J and Gu S: Upregulation of microRNA-96 and its oncogenic functions by targeting CDKN1A in bladder cancer. Cancer Cell Int 15: 107, 2015.

11. Kriebel S, Schmidt D, Holdenrieder S, Goltz D, Kristiansen G, Moritz R, Fisang C, Müller SC and Ellinger J: Analysis of tissue and serum microRNA expression in patients with upper urinary tract urothelial cancer. PLoS One 10: e0117284, 2015.

12. Scheffer AR, Holdenrieder S, Kristiansen G, von Ruecker A, Müller SC and Ellinger J: Circulating microRNAs in serum: Novel biomarkers for patients with bladder cancer? World J Urol 32: 353-358, 2014.

13. Yoshino H, Seki N, Itesako T, Chiyomaru T, Nakagawa $M$ and Enokida H: Aberrant expression of microRNAs in bladder cancer. Nat Rev Urol 10: 396-404, 2013.

14. Yamada Y, Enokida H, Kojima S, Kawakami K, Chiyomaru T, Tatarano S, Yoshino H, Kawahara K, Nishiyama K, Seki N and Nakagawa M: MiR-96 and miR-183 detection in urine serve as potential tumor markers of urothelial carcinoma: Correlation with stage and grade, and comparison with urinary cytology. Cancer Sci 102: 522-529, 2011

15. Zhu G, Wang X, Wu S and Li Q: Involvement of activation of $\mathrm{PI} 3 \mathrm{~K} / \mathrm{Akt}$ pathway in the protective effects of puerarin against $\mathrm{MPP}^{+}$-induced human neuroblastoma SH-SY5Y cell death. Neurochem Int 60: 400-408, 2012.

16. Lv Q, Xue Y, Li G, Zou L, Zhang X, Ying M, Wang S, Guo L, Gao Y, Li G, et al: Beneficial effects of evodiamine on P2X(4)mediated inflammatory injury of human umbilical vein endothelial cells due to high glucose. Int Immunopharmacol 28: 1044-1049, 2015.

17. Dijkstra S, Mulders PF and Schalken JA: Clinical use of novel urine and blood based prostate cancer biomarkers: A review. Clin Biochem 47: 889-896, 2014.
18. Kaboli PJ, Rahmat A, Ismail P and Ling KH: MicroRNA-based therapy and breast cancer: A comprehensive review of novel therapeutic strategies from diagnosis to treatment. Pharmacol Res 97: 104-121, 2015.

19. Guo H, Li Q, Li W, Zheng T, Zhao S and Liu Z: MiR-96 downregulates RECK to promote growth and motility of non-small cell lung cancer cells. Mol Cell Biochem 390: 155-160, 2014.

20. Li Z and Wang Y: MiR-96 targets SOX6 and promotes proliferation, migration and invasion of hepatocellular carcinoma. Biochem Cell Biol: Sep 112017 (Epub ahead of print).

21. Xu L, Zhong J, Guo B, Zhu Q, Liang H, Wen N, Yun W and Zhang L: miR-96 promotes the growth of prostate carcinoma cells by suppressing MTSS1. Tumour Biol 37: 12023-12032, 2016.

22. Cao LL, Xie JW, Lin Y, Zheng CH, Li P, Wang JB, Lin JX, Lu J, Chen QY and Huang CM: miR-183 inhibits invasion of gastric cancer by targeting Ezrin. Int J Clin Exp Pathol 7: 5582-5594, 2014.

23. Xia H, Chen S, Chen K, Huang $\mathrm{H}$ and Ma H: MiR-96 promotes proliferation and chemo- or radioresistance by down-regulating RECK in esophageal cancer. Biomed Pharmacother 68: 951-958, 2014.

24. Hong Y, Liang H, Uzair-Ur-Rehman, Wang Y, Zhang W, Zhou Y, Chen S, Yu M, Cui S, Liu M, et al: miR-96 promotes cell proliferation, migration and invasion by targeting PTPN9 in breast cancer. Sci Rep 6: 37421, 2016.

25. Ma Y, Liang AJ, Fan YP, Huang YR, Zhao XM, Sun Y and Chen XF: Dysregulation and functional roles of miR-183-96-182 cluster in cancer cell proliferation, invasion and metastasis. Oncotarget 7: 42805-42825, 2016.

26. Eissa S, Matboli M, Essawy NO and Kotb YM: Integrative functional genetic-epigenetic approach for selecting genes as urine biomarkers for bladder cancer diagnosis. Tumour Biol 36: 9545-9552, 2015

27. Li C, Du X, Tai S, Zhong X, Wang Z, Hu Z, Zhang L, Kang P, Ji D, Jiang X, et al: GPC1 regulated by miR-96-5p, rather than miR-182-5p, in inhibition of pancreatic carcinoma cell proliferation. Int J Mol Sci 15: 6314-6327, 2014.

28. Lowe SW and Lin AW: Apoptosis in cancer. Carcinogenesis 21: 485-495, 2000

29. Croce CM and Reed JC: Finally, an apoptosis-targeting therapeutic for cancer. Cancer Res 76: 5914-5920, 2016

30. Yu N, Fu S, Liu Y, Xu Z, Liu Y, Hao J, Wang B and Zhang A: miR-96 suppresses renal cell carcinoma invasion via downregulation of Ezrin expression. J Exp Clin Cancer Res 34: 107, 2015.

31. He FZ, McLeod HL and Zhang W: Current pharmacogenomic studies on hERG potassium channels. Trends Mol Med 19: 227-238, 2013

32. Sanguinetti MC: HERG1 channel agonists and cardiac arrhythmia. Curr Opin Pharmacol 15: 22-27, 2014.

33. Litan A and Langhans SA: Cancer as a channelopathy: Ion channels and pumps in tumor development and progression. Front Cell Neurosci 9: 86, 2015

34. Warmke JW and Ganetzky B: A family of potassium channel genes related to eag in Drosophila and mammals. Proc Natl Acad Sci USA 91: 3438-3442, 1994.

35. Lastraioli E, Lottini T, Bencini L, Bernini M and Arcangeli A: hERG1 potassium channels: Novel biomarkers in human solid cancers. Biomed Res Int 2015: 896432, 2015.

36. Lastraioli E, Perrone G, Sette A, Fiore A, Crociani O, Manoli S, D'Amico M, Masselli M, Iorio J, Callea M, et al: hERG1 channels drive tumour malignancy and may serve as prognostic factor in pancreatic ductal adenocarcinoma. Br J Cancer 112: 1076-1087, 2015.

37. Pillozzi S and Arcangeli A: Physical and functional interaction between integrins and hERG1 channels in cancer cells. Adv Exp Med Biol 674: 55-67, 2010.

38. Zeng W, Liu Q, Chen Z, Wu X, Zhong Y and Wu J: Silencing of hERG1 gene inhibits proliferation and invasion, and induces apoptosis in human osteosarcoma cells by targeting the NF- $\kappa \mathrm{B}$ pathway. J Cancer 7: 746-757, 2016.

39. Feng J, Yu J, Pan X, Li Z, Chen Z, Zhang W, Wang B, Yang L, $\mathrm{Xu} \mathrm{H}$, Zhang $\mathrm{G}$ and $\mathrm{Xu} \mathrm{Z}$ : HERG1 functions as an oncogene in pancreatic cancer and is downregulated by miR-96. Oncotarget 5 : 5832-5844, 2014 